Regards sur l'économie allemande

Bulletin économique du CIRAC

$100 \mid 2011$

Varia

\title{
Parité : les quotas ne sont pas la bonne réponse
}

Isabelle Bourgeois

\section{OpenEdition}

Journals

Édition électronique

URL : http://journals.openedition.org/rea/4231

DOI : $10.4000 /$ rea.4231

ISBN : 978-2-8218-0894-2

ISSN : 1965-0787

Éditeur

CIRAC

Édition imprimée

Date de publication : 17 mars 2011

Pagination : 53-51

ISSN : 1156-8992

Référence électronique

Isabelle Bourgeois, "Parité : les quotas ne sont pas la bonne réponse», Regards sur l'économie allemande [En ligne], 100 | mars 2011, mis en ligne le 19 septembre 2011, consulté le 15 septembre 2020. URL : http://journals.openedition.org/rea/4231

Ce document a été généré automatiquement le 15 septembre 2020

(C) CIRAC 


\title{
Parité : les quotas ne sont pas la bonne réponse
}

\author{
Isabelle Bourgeois
}

1 «Bruxelles » fait pression sur les Etats de l'UE pour qu'ils forcent leurs sociétés cotées en bourse à faire une part plus belle aux dirigeantes. Le 8 mars, la Commissaire européenne en charge de la Justice leur donnait douze mois pour remplir l'objectif de 30 \% de femmes dans les directoires à l'horizon 2015 grâce à l'auto-régulation, faute de quoi elle se verrait contrainte de recourir à la réglementation.

\section{Querelle au sein du gouvernement fédéral, ...}

2 La chancelière Angela Merkel, qui déplore que l'Allemagne ait trop peu de femmes aux commandes dans les sociétés du DAX, refuse pourtant farouchement l'idée de quotas. Le 2 mars, elle avait fait savoir par son porte-parole "qu'il n'y aurait pas de contrainte légale via des quotas ", mettant ainsi un termeaux querelles que se livraient deux de ses ministres: Ursula von der Leyen (CDU, Travail) et Kristina Schröder (CDU, Famille), ainsi que la vice-présidente du SPD et ministre des Affaires sociales du Land de Mecklembourg, Manuela Schwesig. La ministre fédérale du Travail est pour, ainsi que sa collègue du gouvernement de Schwerin. Quant à la ministre fédérale de la Famille, elle est contre, considérant notamment qu'un quota légal et uniforme ne tient pas compte des particularités et besoins spécifiques des branches.

\section{... entre les partis et dans leur sein même}

Les lignes de front dépassent les clivages politiques. Si les Verts, la gauche et le syndicat ver.di sont pour une contrainte légale, ils trouvent appui à l'Agence fédérale pour l'emploi dont un des membres du directoire (Heinrich Alt) estime que seule une loi permettra à long terme de faire bénéficier l'économie des hautes qualifications féminines. Quant à l'opposition aux quotas, elle s'étend du FDP (parti de coalition) et de son ministre fédéral de l'Economie, Rainer Brüderle, opposé au principe, jusqu'aux 
grandes fédérations comme celle des CCI (la DIHK) ou celle du patronat (BDA) qui jugent les quotas irréalistes car inappropriés aux besoins des entreprises. Bien entendu, on observe, au sein même de ce camp, une ligne de partage sexuée, les femmes plaidant souvent pour une mesure légale...

\section{L'auto-régulation prime en Allemagne}

Mais l'opposition aux quotas a des raisons plus profondes. Dans un pays comme l'Allemagne dont la culture et la gouvernance institutionnelle sont établies sur le contrat, on recourt normalement à l'auto-régulation, expression la plus pure de l'autonomie des acteurs économiques, elle-même fondée sur le principe de subsidiarité. Les entreprises préfèrent donc se doter elles-mêmes d'instruments pour faire progresser la parité (voir l'analyse de C. Kleinert dans REA 97/10), certaines sociétés du DAX allant jusqu'à instaurer des quotas en interne (par exemple $30 \%$ de femmes en position dirigeante d'ici 2015 chez Deutsche Telekom). C'est là pourquoi Kristina Schröder préfère des solutions conciliant auto-régulation et réglementation, logiques du contrat et de la réglementation.

\section{Obstacle $n^{\circ} 1$ à la carrière : la maternité}

5 Mais cela reste largement insuffisant pour hisser un plus grand nombre de femmes dans les postes à responsabilités - et ce, à temps plein. Le principal obstacle reste la maternité. Certes, Destatis fait état de $72 \%$ de mères actives dans la tranche d'âge des 25-49 ans, mais ce taux ne concerne que celles ayant un seul enfant (de moins de 25 ans). Car dès que le nombre d'enfants augmente, le taux d'activité se réduit; il n'est plus que de $53 \%$ lorsque le foyer compte au moins 3 enfants (communiqué du 8 mars). Cela dit, ces taux ne font pas la différence entre temps plein et temps partiel, et incluent dans la période d'activité les congés maternité. Enfin, ils ne précisent pas le type d'emploi occupé. Ils ne sont donc guère pertinents pour ce dossier.

\section{Un thème politique symbolique car irréaliste}

6 Plus révélateurs sont les chiffres publiés dans le quotidien F.A.Z. par Renate Köcher (Allensbach-Analyse du 24-02-11) qui considère la difficile conciliation entre vies professionnelle et familiale et pointe la contradiction entre "réalité et politique symbolique ». $84 \%$ des mères de moins de 45 ans interrogées par son institut ont interrompu leur activité au moins une fois ; chez les pères, ce taux est d'à peine $10 \%$. Si dans cette tranche d'âge, $48 \%$ des femmes occupent un temps plein, ce n'est le cas que pour une mère sur trois.

\section{Obstacle $n^{\circ} 2$ : le partage des rôles}

7 Les raisons expliquant que la majorité des mères préfère un temps partiel ou l'inactivité sont avant tout culturelles: $59 \%$ des femmes de moins de 45 ans considèrent la combinaison maternité/temps partiel comme un choix personnel idéal. Dans la représentation qu'on a du rôle de la mère outre-Rhin, élever un enfant en bas 
âge tout en exerçant un temps plein est en effet considéré comme dommageable à l'enfant. C'est cela qui ancre si profondément dans la culture et l'économie allemandes le partage des rôles entre femmes et hommes ; c'est cette rémanence du modèle du père apportant le revenu familial qui rend si difficile la conciliation des vies familiale et professionnelle (voir l'analyse de W. Eichhorst et E. Thode dans REA 96/10) et qui constitue le véritable handicap à l'accession des femmes aux postes à responsabilités. Cela est beaucoup moins vrai toutefois dans l'est de l'Allemagne où, pour des raisons historiques et structurelles (infrastructures d'accueil de la petite enfance plus développées), l'activité des femmes avait et a toujours une image plus porteuse. $\mathrm{Ou}$ encore dans d'autres pays de l'UE, comme la France par exemple.

\section{Les Allemands préfèrent l'équité des chances}

8 Voilà pourquoi en Allemagne de l'ouest, $72 \%$ des mères et $68 \%$ des pères d'enfants de moins de 18 ans affirment qu'il est difficile, voire impossible de concilier vies familiale et professionnelle; pour l'ensemble de la population (sans distinction de sexe ou de charge de famille), ce taux est de $63 \%$. Les vraies résistances à une plus forte implication des femmes, a fortiori dans les fonctions dirigeantes, sont culturelles. C'est ce qui amène l'auteur de cette analyse, la directrice de l'Institut für Demoskopie d'Allensbach, à regretter que cet état de fait soit «oublié ou volontairement ignoré» dans le débat actuel sur les quotas. Comparé à l'ampleur et à la réalité des défis pour accroître la participation des femmes (améliorer les structures d'accueil à l'enfance, rompre avec la stigmatisation de la mère active, susciter l'émergence de cultures d'entreprises plus respectueuses des familles), débattre de l'adoption de quotas tient plus du "débat de façade» et d'une "politique symbolique» que "d'une discussion approfondie de la nature véritable des problèmes». A preuve: ces débats sont plus qu'éloignés des préoccupations des Allemands dont les deux tiers (66\%) pensent que le choix des candidats à un poste de dirigeant doit obéir exclusivement à des critères de qualification et de performance. Et quand on leur demande comment accroître l'équité des chances, alors $62 \%$ des hommes et $56 \%$ des femmes disent que ce qui compte pour eux, c'est que les emplois qui ont la prédilection des femmes présentent les mêmes perspectives de carrière et d'évolution de salaire que ceux qu'occupent majoritairement les hommes.

\section{INDEX}

Mots-clés : parité, égalité des chances, égalité des sexes, groupe social, femme, pouvoir politique, gouvernement, famille, marché du travail, marché de l'emploi, emploi 